\title{
Characteristic Changes Defined via Comparison of the Big-Five Personalities in Japanese University Freshmen from Years 2000 to 2016
}

\author{
Kayo Shichiri' ${ }^{1}$ Akira Tachibana', Hiroko Abe ${ }^{2}$, Takuro Kunizuka², Yuri Yoshida' \\ Chikako Tomiyama ${ }^{3}$, Mayumi Watanabe ${ }^{4}$
}

\author{
${ }^{1}$ Health Administration Center, Headquarters for Health Administration and Environmental Safety, Niigata University, \\ Niigata, Japan \\ ${ }^{2}$ Department of Psychiatry, Niigata University Graduate School of Medical and Dental Sciences, Niigata, Japan \\ ${ }^{3}$ Department of Medical Technology, Graduate School of Health Sciences, Niigata University, Niigata, Japan \\ ${ }^{4}$ Chuo University, Tokyo, Japan \\ Email: shichiri@med.niigata-u.ac.jp
}

How to cite this paper: Shichiri, K., Tachibana, A., Abe, H., Kunizuka, T., Yoshida, Y., Tomiyama, C. and Watanabe, M. (2017) Characteristic Changes Defined via Comparison of the Big-Five Personalities in Japanese University Freshmen from Years 2000 to 2016. Health, 9, 1348-1354.

https://doi.org/10.4236/health.2017.910098

Received: August 2, 2017

Accepted: September 19, 2017

Published: September 22, 2017

Copyright (c) 2017 by authors and Scientific Research Publishing Inc. This work is licensed under the Creative Commons Attribution International License (CC BY 4.0).

http://creativecommons.org/licenses/by/4.0/

\begin{abstract}
Introduction: With the arrival of the $21^{\text {st }}$ century, drastic worldwide changes to natural, economic and social events have occurred. These include the Great East Japan Earthquake, and the global financial crisis. Furthermore, Japan experienced the introduction of a specific education system. In this study, we traced and compared the psychological characters of university freshmen for 16 years (years 2000-2016) using Big-Five personalities inventory (Japanese version). Methods: A total of 1189 physically and mentally healthy university freshmen participated in this study. They were divided into four groups according to the year they entered university. They completed a self-filled questionnaire, Big-Five personalities inventory, which consists of Extraversion, Agreeableness, Neuroticism, Conscientiousness and Openness. Result and Discussion: Compared with the year 2008, Extraversion nominally increased in 2012, however, it statistically significantly decreased in 2016. Agreeableness notably decreased from 2000 to 2008, then showed an increase in 2012. Compared to 2000, Neuroticism was statistically significantly lower in 2008 and 2016. Such statistically significant differences were not observed in the other two personalities. The personalities of university freshmen have changed in the last 16 years, which may be been caused by drastic changes. However, further research (e.g., larger-scale studies or studies including other university students) is required to support the current findings.
\end{abstract}

\section{Keywords}

Characteristic Changes, Big-Five Personalities, University Freshmen, 


\section{Introduction}

Social or economic circumstances can affect the physical development of university students. In particular, university students' psychological profile has been affected by the "lost two decades", which introduced drastic worldwide changes due to social and economic events. In recent years, faculty staff have sometimes expressed fear that psychological criteria of university freshmen have changed in the last 16 years from the year 2000. However, some philosophers have proposed the following hypothesis: a material developed society leads to people who are psychologically undeveloped [1] [2] [3].

To examine this hypothesis in detail, we assayed and traced the psychological character profiles of university freshmen for 16 years using the Japanese version of the Big-Five personalities scale.

Goldberg and colleagues established the idea of a five-factor model of personalities, which led to the invention of a self-filling questionnaire called the Big-Five personalities inventory [4] [5] [6]. This inventory consists of the following categories: Extraversion, Agreeableness, Conscientiousness, Neuroticism, and Openness. Goldberg's team investigated, defined and encoded these personalities as single words, emphasizing them as being the most important to peoples' lives. Furthermore a lexical hypothesis was established.

Murakami $\mathrm{Y}$ and Murakami C developed the Japanese version of the Big-Five personalities inventory to make it more suitable to assay the specific personalities of Japanese people. Now widely used in Japan [7] [8], "Big-Five" personality scale assays/describes aspects of Japanese personalities [10] [11] [12]. In this study, we traced results from the Japanese version of the Big-Five for 16 years.

\section{Methods}

\subsection{Participants}

Participants ( $\mathrm{n}=1189$; male 810 , female 379 ) were physically and mentally healthy university freshmen. All participants were informed of the purpose and nature of the experiments; then written consent was obtained from each participant, in compliance with the World Medical Association Declaration of Helsinki. The study was also approved by the institutional review board of Niigata University (Niigata, Japan). They were voluntary students. They responded to our invitation of this study, through mental screening test: MINI-27 [9], excluded severe depressive, nervous tendency and stress symptoms.

\subsection{Maintaining Specification Integrity}

All participants were either 18 or 19 years of age. This investigation continued for 16 years from 2000 to 2016 and participants were divided into four groups 
according to the year they entered Niigata University. As concerns their sociodemographic background, all of them were unmarried and their parents belonged to middle or upper classes. Their detailed profiles are shown in Table 1.

\subsection{Profile of the Big-Five Inventory (Japanese Version)}

To investigate participants' character, participants answered 70 items from the Big-Five personality inventory (Japanese Version), including Extraversion, Agreeableness, Neuroticism, Conscientiousness and Openness [7]. The Big-Five inventory is an often-used and reliable measure of personality [10] [11] [12] [13]. Its Japanese version is considered to be more reliable than the original English version for Japanese participants [13]. Samples were randomly selected country-wide and appropriate age-group-stratified standardization was performed [8]. The inventory provides a standardized score (mean, 50; standard deviation), for each factor [12].

\subsection{Characteristics of the Big-Five Personalities}

The characteristics of the Big-Five personalities are defined below [7].

1) Extraversion: a person with Extraversion personality generally experiences positive emotions, is assertive, sociable and tends to seek stimulation in the company of others.

2) Agreeableness: a person who is categorized with Agreeableness tends to be compassionate and cooperative rather than suspicious and antagonistic towards others. This tendency is also a measure of one's trusting and helpful nature, and whether a person is generally well-tempered or not.

3) Neuroticism: a person who is considered to have Neuroticism tends to experience unpleasant emotions easily, such as anger, anxiety, depression and vulnerability. In this personality type, emotional stability and impulse control are often observed. (On Japanese version, high scores of this personality type describe emotional stability.)

4) Conscientiousness: a person who is categorized with Conscientiousness shows a tendency toward being organized and dependable, with self-discipline and acts dutifully. In other words, such a person prefers plan rather than spontaneous behavior.

5) Openness: a person with Openness shows unusual ideas, emotion, adventure, curiosity, and variety of experience. This personality shows intellectual curiosity, creativity, preference for novelty, being imaginative or independent.

Table 1. Participants' profiles.

\begin{tabular}{ccccc}
\hline year & average age (years old) & male (810) & female (379) & total (1189) \\
\hline 2000 & $18.4 \pm 0.5$ & 339 & 51 & 390 \\
2008 & $18.2 \pm 0.4$ & 306 & 90 & 396 \\
2012 & $18.3 \pm 0.5$ & 81 & 124 & 205 \\
$\mathbf{2 0 1 6}$ & $18.6 \pm 0.6$ & 84 & 114 & 198
\end{tabular}




\subsection{Statistical Analysis}

ANOVA test was conducted and the level of significance was set at $p<0.05$. The values presented were expressed as a range with mean \pm SD. All statistical analyses were performed using SPSS Statistics for Windows version 22.0 (IBM Corp, Armonk, NY).

\section{Results}

Figure 1 presents the results of the Big-Five inventory.

Extraversion nominally increased from the year 2008 to $2012(44.7 \pm 8.6 \rightarrow$ $47.5 \pm 10.3, p<0.01)$, however, Extraversion statistically significantly decreased from 2012 to $2016(47.5 \pm 10.3 \rightarrow 44.2 \pm 9.9, p<0.01)$.

Agreeableness notably decreased from 2000 to 2008 (50.8 $\pm 8.9 \rightarrow 49.2 \pm 9.0$, $p<0.05)$, then increased from 2008 to $2012(49.2 \pm 9.0 \rightarrow 52.6 \pm 9.3, p<0.01)$. A statistically significant increase was observed from 2008 to 2016 (49.2 $\pm 9.0 \rightarrow$ $51.4 \pm 9.0, p<0.05)$.

Neuroticism nominally decreased from 2000 to 2008 (50.6 $\pm 9.9 \rightarrow 47.5 \pm 8.6$, $p<0.01)$ and statistically significantly decreased from 2000 to $2016(50.6 \pm 9.9 \rightarrow$ $47.9 \pm 9.5, p<0.05)$.

Statistically significant differences were not observed in the two other personalities. Conscientiousness decreased from $53.4 \pm 10.1$ in 2000 to $53.3 \pm 8.7$ in 2008, and from $52.7 \pm 9.6$ in 2012 to $51.9 \pm 9.2$ in 2016. Openness increased
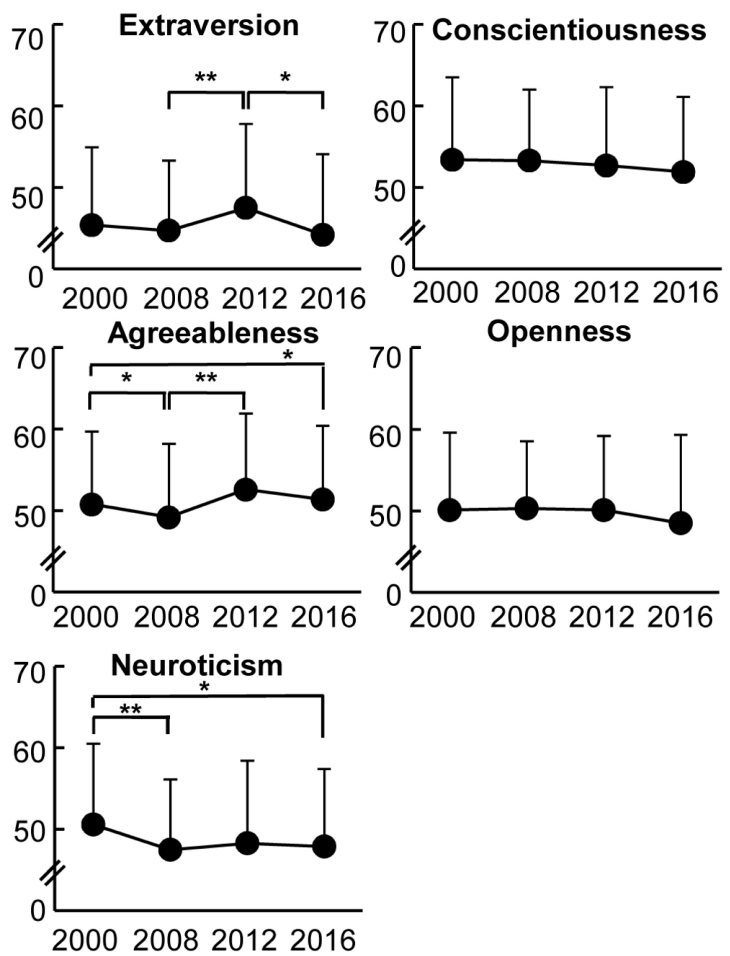

Figure 1. Comparison the big-five of personalities of university freshmen for the last 16 years from the year 2000: ${ }^{\star} p<0.05,{ }^{\star *} p<0.01$. 
from $50.1 \pm 9.5$ in 2000 to $50.3 \pm 8.2$ in 2008 , and decreased from $50.1 \pm 9.1$ in 2012 to $48.5 \pm 10.8$ in 2016 .

The average scores of all Big-Five personalities remained within the range of $45-55$.

There were not any differences between the average scores of all Big-Five personalities for gender.

\section{Discussion}

Our results demonstrated that the personalities of university freshmen changed over time. In short, Extraversion, Agreeableness and Neuroticism changed within the last 16 years despite the age of the participants remaining unchanged at the university also remaining unchanged. In other words, those who have either of these three personalities may cope quickly with changes over times.

\subsection{Extraversion and Agreeableness during a Specific Catastrophic Event}

Scores for Extraversion and Agreeableness were the highest in 2012. On 11 March 2011, the Great East Japan Earthquake struck the Northern/Eastern region of Japan. The earthquake was caused by several quake focal areas that moved simultaneously, producing an intensity that occurs only once every 1000 years. More than 20,000 people died as a result. The students in our study experienced this devastating event just 1 year prior to entering university and surely remembered it. Empirically, they realized that the "bond", that linked them to one another was not of blood, but of respect for each other's lives. This specific experience may have caused the change observed in Extraversion and Agreeableness.

\subsection{Neuroticism Might Be Affected by Economic/Social Circumstances}

Neuroticism was observed to decrease since 2000. The reason for this downward trend could be explained by the 2008 financial crisis of the Lehman Brothers crash. According to the Ministry of Health, Labour and Welfare (Japan), 10\% of female graduates give up their careers in their 30 s and less than $60 \%$ of them retain full-time employment in their 40s due to responsibilities such as raising children or caring for elderly parents [14] [15]. Thus, university freshmen face unemployment unrest, a dwindling birth rate and an aging population. Such economic/social circumstances may have affected the results of Neuroticism.

\subsection{Conscientiousness and Openness Showed No Nominal Differences}

Statistically significant differences were not observed in the two personalities of Conscientiousness and Openness. Additionally, all average scores of all Big-Five personalities stayed within the normal range (45 - 55) [7]. 
The participants of the current study belong to Niigata University, which is a Japanese national university located in Eastern Japan. Students must pass a highly competitive entrance exam for acceptance into the university. In short, all of our participants may be considered to be successful individuals with adequate level of Conscientiousness/Openness, as well as a normal range of health.

Another possible explanation for the difference observed between the year 2000 group and the other three groups could be found in the specific education system called yutori. This yutori system was designed to relieve the pressure experienced by students and to broaden their perspective and creative abilities. Participants who belonged to years 2008, 2012 and 2016 received this type of education before entering university.

Our study has several limitations. First, the number of participants was limited; therefore, further research (e.g., larger-scale studies or studies including other university students) is required to support these findings. Second, to avoid the specific influence of the 2008 financial crisis or 2011 catastrophic event, continued investigation is needed to compare current data with that of future students (e.g., until-2020 or 2024). Further data could confirm the null hypothesis: the psychological character of university freshmen has declined in the last 16 years.

\section{Acknowledgements}

The authors thank all of the study participants. This work was supported by JSPS KAKENHI Grant Numbers JP16K01786.

\section{References}

[1] Saito, T. (2013) Hikikomori: Adolescence without End. Angles, J., Translation, University of Minnesota Press, MN. ISBN-10: 081665459X, ISBN-13: 978-0816654598

[2] Saito, T. (2010) Hakushi no Kimyo na Seijuku; Subculture and Social Psychopathology. Nippon HyoronSha Co., Ltd. Tokyo, Japan. ISBN-10: 4535562865, ISBN-13: 978-4535562868. (In Japanese)

[3] Szasz, T.S. (1974) The Myth of Mental Illness. 2nd Edition, Harper \& Row Publishers, Inc., New York.

[4] Goldberg, L.R. (1990) An Alternative "Description Of Personality": The Big-Five Factor Structure. Journal of Personality and Social Psychology, 59, 1216-1229. PMID: 2283588. https://doi.org/10.1037/0022-3514.59.6.1216

[5] Hofstee, W.K., de Raad, B. and Goldberg, L.R. (1992) Integration of the Big Five and Circumflex Approaches to Trait Structure. Journal of Personality and Social Psychology, 63, 146-163. PMID: 1494982. https://doi.org/10.1037/0022-3514.63.1.146

[6] Goldberg, L.R. (1993) The Structure of Phenotypic Personality Traits. American Psychologist, 48, 26-34. PMID: 8427480. https://doi.org/10.1037/0003-066X.48.1.26

[7] Murakami, Y. and Murakami, C. (1997) Scale Construction of a 'Big-Five' Personality Inventory. The Japanese Journal of Personality, 6, 29-39.

https://doi.org/10.2132/jjpjspp.6.1_29 
[8] Murakami, Y. and Murakami, C. (1999) The Standardization of a Big Five Personality Inventory for Separate Generations. The Japanese Journal of Personality, 8, 3-42. https://doi.org/10.2132/jjpjspp.8.1_32

[9] Murakami, Y. and Murakami, C. (1992) Computer Psycho-Diagnostic System; Invitation to MINI, MMPI-1, Automatic Diagnostic System. Gakugei Tosho Co., Ltd. Tokyo, Japan. ISBN-10: 476160221X, ISBN-13: 978-4761602213. (In Japanese)

[10] Sorimach, T. and Maruyama, T. (2016) The Relationship between Preparation Behavior and Personality Traits of Vocational School Students in Using a Preparation Video for Classes-Focusing on the Big Five Personality Traits. Journal of the Society of Physical Therapy Science, 31, 233-238. http://doi.org/10.1589/rika.31.233

[11] Kitajima, M., Hirabe, M., Fujihiro, Y., Ymagiwa, K. and Kuwata, Y. (2012) The Habit of Milk Consumption among Adolescent from a Perspective of Personality. The Japan Society of Health Sciences of Mind and Body, 8, 143-149. http://doi.org/10.11427/jhas.8.143

[12] Kitamura, H., Shindo, M., Tachibana, A., Honma, H. and Someya, T. (2013) Personality and Resilience Associated with Perceived Fatigue of Local Government Employees Responding to Disasters. Journal of Occupational Health, 55, 1-5. http://doi.org/10.1539/joh.12-0095-BR

[13] Oshio,A., Abe,S. and Cutrone, P. (2012) Development, Reliability, and Validity of the Japanese Version of Ten Item Personality Inventory (TIPI-J). The Japanese Journal of Personality, 21, 40-52. http://doi.org/10.2132/personality.21.40

[14] Shichiri, K., Shibuya, M., Watanabe, M., Tahashi, M., Kaminushi, K., Uenoyama, T., Mashima, I., Murayama, K., Kuroda, T. and Suzuki, Y. (2016) Correlations between the Profile of Mood States (POMS) and the WHOQOL Japanese University Students. Health, 8, 416-420. https://doi.org/10.4236/health.2016.85044

[15] Japanese Ministry of Health, Labour and Welfare (2009) Daisotsu-Josei no hataraki-kata Hataraku-Josei no Jitsujo (Japanese). The Way Female Graduates Work the Current Condition of Career Woman. Japanese Ministry of Health, Labour and Welfare. http://www.mhlw.go.jp/houdou/2009/03/dl/h0326-1d.pdf

Submit or recommend next manuscript to SCIRP and we will provide best service for you:

Accepting pre-submission inquiries through Email, Facebook, LinkedIn, Twitter, etc. A wide selection of journals (inclusive of 9 subjects, more than 200 journals)

Providing 24-hour high-quality service

User-friendly online submission system

Fair and swift peer-review system

Efficient typesetting and proofreading procedure

Display of the result of downloads and visits, as well as the number of cited articles

Maximum dissemination of your research work

Submit your manuscript at: http://papersubmission.scirp.org/

Or contact health@scirp.org 